\title{
Branch Updates
}

\section{Shaun Crawley, CPHI(C) President, CIPHI NB Branch}

Greetings, as summer moves along, I hope everyone has been able to take some time off and enjoy the weather even though the work of PHIs goes into overdrive during the warmer months. The addition of beaches, swimming pools, summer camps, special events, and the like on top of all our usual work make this a hectic time of year. Spring was also busy for PHIs from across New Brunswick. We were once again involved in flood response as the province was hit with significant spring flooding for a second consecutive year while at the same time helping our public health colleagues responding to a measles outbreak in the southwest part of the province.

A long-time member and councilor within the NB Branch has decided to step down from his current role with the Branch Executive. Murray Lewis who has been a part of the NB Branch for many years, most recently as the retiree councilor on the Executive, has decided to move on. The Branch Executive would like to thank Murray for his time with the NB Branch and wish him well.

As mentioned in the last Branch update, this year's NB Branch Annual Educational Session will be held in northern New Brunswick. The City of Edmundston has been selected as this year's venue. The annual education session is being held from October 16 to 18. Also, a Facebook page has been created for the NB Branch that will be used to communicate with our members. We are still in the early stages of adding content but look us up! Finally, with this year's national educational session next door in Halifax, Nova Scotia, we are hoping to have a good group representing New Brunswick, and I look forward to reconnecting with friends and colleagues from across Canada. Hope to see you there.

\section{John Cannan President, CIPHI Ontario Branch}

The summer heat has finally kicked in here in Ontario and more than the weather has been heating up. In April the Ontario government announced they were cutting the public health budget by $\$ 200$ million dollars. Plans were also announced that the 35 Ontario health units would be amalgamated into 10 Regional Public Health Entities (RHPEs).
As public health staff across the province reacted to this news, CIPHI Ontario kept pace with some advocacy work asking to work with the government during these times of change. Near the end of May, the Ontario government announced that the budget cuts would be cancelled for 2019. What will happen over the next year is unknown, but we will continue to work with our partners, stakeholders, and hopefully the government to ensure that properly trained inspectors are on the job protecting the health of all Ontarians.

We are currently experiencing temperatures in excess of $30^{\circ} \mathrm{C}$, which is quite the change from the heavy rains and flooding we had this spring. These drastic variations in the climate are one of the reasons why CIPHI Ontario has become involved in several climate change initiatives.

First, Helen Doyle, a retired PHI from York Region Public Health, is representing CIPHI Ontario on the health-focused Climate Communications Campaign advisory committee. The campaign \#MakeItBetter was designed to engage health agencies and the general public in climate action and to share information and resources to protect families and communities from the health impacts of climate change. For more information check out https://makeitbetterontario.ca

CIPHI Ontario is also endorsing the nonpolitical, Call to Action on Climate Change and Health from the Canadian Association of Physicians for the Environment (CAPE). The call to action currently involves the Canadian Medical Association (CMA), the Canadian Nurses Association (CNA), the Canadian Public Health Association (CPHA), and the Urban Public Health Network (UPHN). The call to action's message identifies several measures to be implemented that were delivered to each of the four federal political parties.

The April Board of Certification certified 11 new Public Health Inspectors. I would like to congratulate these new inspectors and wish them luck with their future endeavours.

While the work is on-going there is still time for some fun and games and that is exactly what took place on June 21 as Ottawa Public Health hosted this year's annual softball tournament. Nine teams from across Ontario participated including a team of students from Conestoga College in Kitchener. The final game came down to Simcoe Muskoka and Conestoga College, with the students taking home the championship. The students have even offered to host the 2020 softball tournament. I look forward to seeing all the players in Kitchener next year. 